\title{
Application of the technique of the social innovative-and-investment projects efficiency assessment in the municipal sphere
}

\author{
Valeriya Glazkova ${ }^{1, *}$ \\ ${ }^{1}$ Moscow State University of Civil Engineering, Yaroslavskoe shosse, 26, Moscow, 129337, Russia
}

\begin{abstract}
Development of the social sphere is often connected with the creation of new municipal facilities: schools, hospitals, higher education institutions, institutions of culture and sports, infrastructure. The approach to the assessment of the results of innovative-and-investment projects in the social sphere, offered in the article, is connected with the solution of some methodical matters of the formation of the system of indicators, which are adequately reflecting improvement of functioning of the municipal social facilities. The technique of the assessment of the efficiency of social innovative-and-investment projects, which are resulted in mechanism allowing to select social oriented projects, including those of the municipal sphere for the realization is presented.
\end{abstract}

\section{Introduction}

According to the Strategy of development for the Russian Federation ensuring high welfare of the population is one of its priority directions. The possible way of achievement of this purpose is the transition of the economy to the innovative socially oriented model of development declared in Strategy.

Innovations become one of the main driving forces in development of national economy, influence structure of social production, are the important element in development of all spheres of activity of society including the social sphere.

The social sphere is capable to accumulate direct and indirect consequences of innovative transformations which can come back as a boomerang to economic practice of the person through consciousness and behavior of people [1].

G. Tard investigated value of inventions in social progress, the relation of society to inventions and innovations. In the theory of "big cycles" of the economist N. D. Kondratyev, it is noted that inventions and innovations exert powerful impact on all course of economic dynamics and on social progress in particular [2].

P. Rozanvallon and B. Santo have suggested to consider the most important problems of the present through a prism of "sociality", assigning a significant role to social innovations [3]. P. Druker and M. Young considered social innovations to be the fundamental moment of social business.

\footnotetext{
*Corresponding author: leram86@mail.ru
} 
The innovative component of the implementation of social oriented projects can become one of fundamental factors of successful development of the social sphere, and, as a result, promote increase in level and quality of life of the population.

As innovative activity, as a rule, is implemented and copes within investment projects of innovative character, consideration of projects as innovative and investment is necessary.

The Social Innovative and Investment Project (SIIP) is considered as a complex of actions and activities (works, services, acquisitions, administrative operations and decisions) directed to the improvement of life quality and satisfaction of social needs of the interested participants as the result of implementation of the technical, organizational and marketing innovations to the social sphere and demanding for the realization of implementation of investments [4]. In the absence of implementation of innovations, the project takes a private form of the social investment project.

The existing practice of the assessment of efficiency of innovative-and-investment projects to the social sphere not fully considers social consequences of implementation of the project that, often, reduces their importance and leads to insufficient financing. In this regard, the technique of an assessment of efficiency of social innovative and investment projects promoting more productive planning and the subsequent implementation of projects in the municipal sphere is developed.

\section{Methods}

The use of the offered technique is expedient for the assessment of efficiency of social innovative-and-investment projects, and also for comparison of alternative projects as well as the choice of the best option.

The offered technique of the assessment of efficiency of SIIP is intended for evaluating and selection of the innovative-and-investment projects realized in the social sphere with participation of means of both public and private organizations and also for commercial innovative-and-investment projects regarding the assessment of social efficiency from implementation of the project. The technique can be also applied to the assessment of the social investment project (as the special case of the social innovative-and-investment project in the absence of an innovative component).

The assessment of the efficiency of investments in the social innovative-and-investment project, according to this technique, is preceded by justification of the expediency of its realization. Expediency of the project and its compliance to priorities of social-andeconomic development of the region is confirmed at the preliminary stage by the assessment of level and quality of provision of the population with social services, as well as the degree of satisfaction of the population with quality of the social services provided.

The developed technique of the assessment of efficiency of SIIP is constructed on respect for the following principles of the assessment:

- principle accounting of all most substantial effects of the project;

- principle of unity of the assessment of efficiency of investments of the state, business

and society;

- consideration of the project throughout all its life cycle;

- accounting of the factor of time;

- principle of positivity and maximum of effect;

- comparability of conditions of comparison of various projects;

- principle of taking note of uncertainty and risks;

- the principle of the accounting of the effectiveness differentiated in the social directions;

- principle of selective (selective) management;

- principle of the accounting of the importance of a factor [5]. 
As the expenses connected with the implementation of the project the following is considered:

- single capital investments on construction, reconstruction or modernization of a project, including acquisition of the equipment, development of production and implementation of the accompanying works and expenses, and also the implementation of innovations. Also to single expenses direct budgetary appropriations on extra charges can belong to market prices of fuel, energy and natural resources; the budgetary guarantees connected with covering of investment-and-innovative risks to foreign and domestic participants; costs of resettlement or compensation of cost of housing to citizens in connection with implementation of the project;

- operational expenses - the operating costs connected with the maintenance of the entered object or the project providing normal functioning and achievement of the objectives of investment.

The results of the project implementation include:

- quantitative increment of volume of social services, depreciation of services due to possible cut in expenditure on rendering former volume of the corresponding services, economy of budgetary funds, additional receipts from taxes, and also obtaining the accompanying income of the budget from other branches and spheres as a result of implementation of the project;

- high-quality improvement of service of consumers and rendering services, including ensuring their availability, timeliness and rhythm of granting, increase in degree of satisfaction of the population with social security, improvement of the ecological situation, improvement of quality of life of people and creation of conditions for harmonious development of the personality.

\section{Results}

For the assessment of efficiency of SIIP both quantitative, and quality indicators of result of implementation of the project are used.

The general scheme of the assessment of efficiency of social innovative-and-investment projects is submitted by the following algorithm (Figure 1).

During the comparing of alternative social innovative and investment projects and the choice of the most effective option, the algorithm of a comparative rating assessment of projects based on the method of distances is applied. As the reference project the conditional option with the maximum reached values of indicators is accepted. To realization the project having the minimum value of a rating assessment is chosen.

We will notice that some alternative projects, according to the Methodical recommendations about an assessment of efficiency of the investment projects, are understood as mutually exclusive projects (that is acceptance of one of projects automatically means that the remained projects have to be rejected as they apply for the same resources) [6].

The significance value of the project is appropriated according to the level of novelty of an innovation (projects of the 1st significance value have the greatest priority, the 4th significance value - the smallest priority):

4 level - the innovations involved in the project already exist and are intended for the solution of a concrete objective, for improvement of concrete parameters.

3 level - the innovations involved in the project existing, but they are changed and intended for the solution of the new changed task at the new level.

2 level - the innovations involved in the project new, allowing to find the new solution of a new task. 
1 level - the innovations involved in the project open the new ways and the principles of the solution of a task suitable for the decision not only this task, but also other tasks and problems, and also leading to profound changes in the social sphere and life of society.

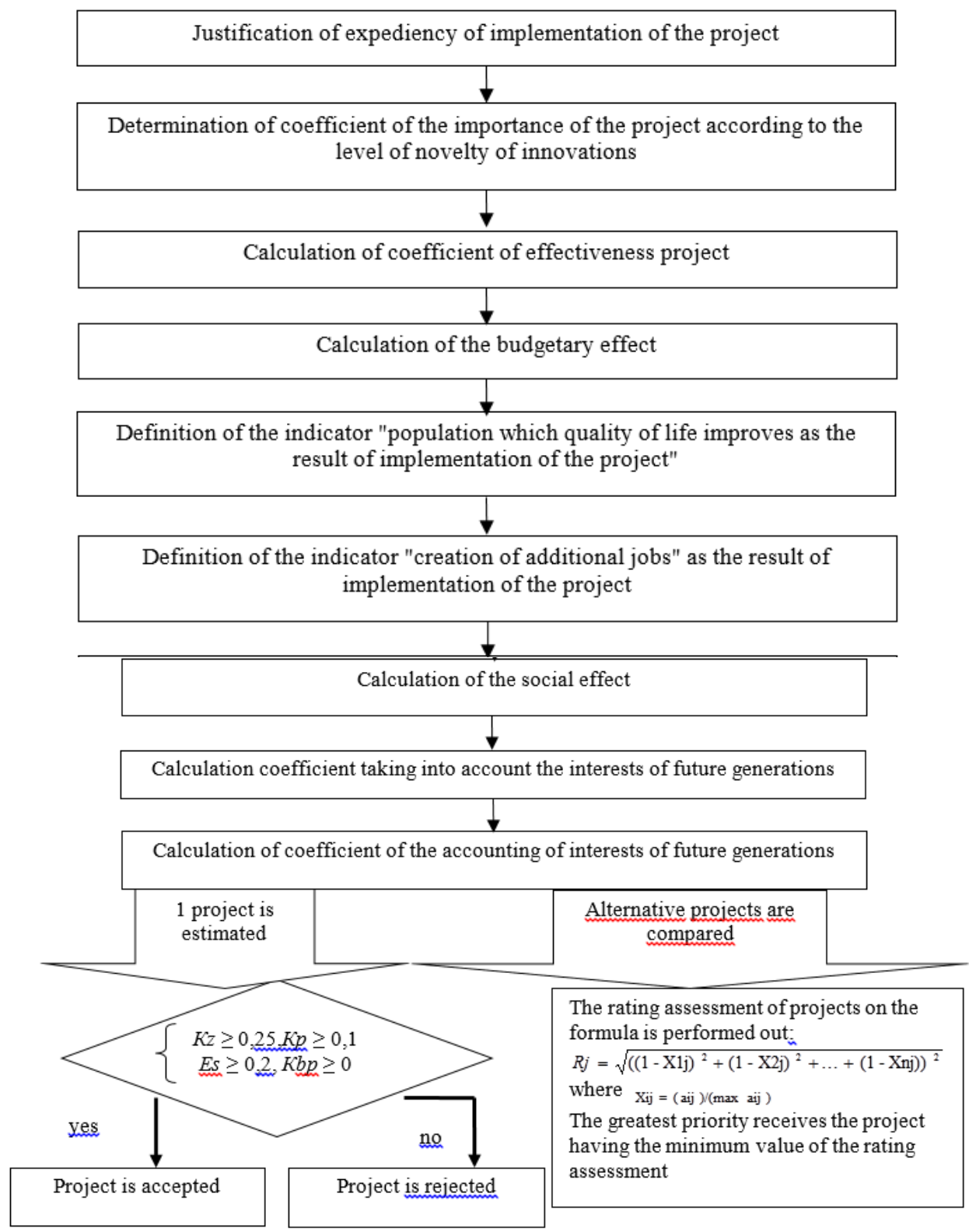

Fig. 1. Algorithm for evaluating the effectiveness of innovative investment projects.

Effectiveness is estimated upon achievement of the social standards characterizing coverage by results of the project, influence of implementation of the project on volume and quality of services, prime cost and cost of services, security with financing, and also influence of implementation of the social project on business. 
The coefficient of effectiveness $(\mathrm{Kp})$ of the social innovative-and-investment project is determined as the result of an expert assessment on the basis of system of indicators by the following Equation:

$$
\begin{aligned}
& K p=I 1 x K u 1+I 2 x K u 2+I 3 x K u 3+I 4 x K u 4 \\
& +I 5 x K u 5+I 6 x K u 6+I 7 x K u 7
\end{aligned}
$$

Where $K p$ - coefficient of effectiveness of the project;

$u 1, u 2, u 3, u 4, u 5, u 6, u 7$ - the values of indicators corresponding to the project on the corresponding group;

$K u 1, K u 2, K u 3, K u 4, K u 5, K u 6, K u 7$ - coefficients on the corresponding group of indicators.

The budgetary efficiency characterizes the influence of the results of the social innovative-and-investment project implementation on the income and expenses of the relevant budget. The purpose of the assessment of the budgetary efficiency is determination of the amount of possible receipts in the budget (the income of the budget), and also the load of the budget for the maintenance of the project or service entered as the result of realization of the SIIP. An indicator of the budgetary efficiency of the SIIP is the budgetary effect which calculation is made on the following formula:

$$
B p=\sum_{i=1 . . n}^{n} \frac{D i}{(1+S r)^{i-1}}-\sum_{i=1 . . n}^{n} \frac{R B i}{(1+S r)^{i-1}}
$$

Where $B p$ - net discounted budgetary effect from the project implementation, rubles

$$
\begin{aligned}
& \sum^{n} \frac{\not D i}{(1+S r)^{i-1}}-\text { the discounted receipts into the budget of the region from the project } \\
& \sum_{i=1 . . n} \frac{\not D i}{(1+S r)^{i-1}}
\end{aligned}
$$

implementation, rubles;

$\sum^{n} \frac{R b i}{(1+S r)^{i-1}}$ - the discounted expenses of the budget of region on the project implementation, rubles;

$S r$-refunding rate of the Bank of Russia at the time of carrying out calculations;

$n$ - time period.

When calculating income and expenses of the budget it is necessary to consider not only the direct results from the project implementation, but the missed benefit, possible economy of the budget and other consequences of implementation of the project. We will notice that, the budgetary effect for the social projects is usually negative as expenses on projects much more exceed the income from their realization. It is connected with the specifics of social projects on which any income is absent or has the minimum value $[7,8,9]$.

Social efficiency includes the assessment of the following indicators: population which quality of life improves as the result of implementation of the social innovative-andinvestment project (people), quantity of the created additional jobs (piece), and also the assessment of private indicators of social efficiency of SIIP (an indicator of social effect).

The indicator population which quality of life improves as the result of the project implementation (Chnasul) pays off for the population which quality of life to improve due to granting bigger volume of services, increase in availability of services or improvement of service according to the project.

The indicator is defined by the direct account on the volume of final services of the invested object or by the assessment of indirect influence from introduction of the SIIP: for example, at implementation of the project in housing sector on input of a new municipal 
project of a certain capacity, population for which quality of service improves, defined on the basis of norm of consumption of service per 1 person; at the implementation of the innovative-and-investment project in education - the total number of the population which will study by a new technique or the program. Number of patients, at implementation of the project on health care facilities to which the treatment or prevention leading to long improvement of health and ability to work, for example, the operated patients and so on, will be rendered.

The indicator "creation of additional jobs" (Jad) is estimated by summation of all newly created jobs as the result of the project implementation, including those in the accompanying branches and spheres in which the increment of quantity of jobs in connection with realization of the SIIP is observed.

According to the technique the system of standards was developed for the assessment of effectiveness of social innovative-and-investment projects in the following spheres: education, health care, transport, housing and communal services, culture, physical culture and sports.

As according to T. Saati, "the ability of the person to distinguish is in very limited range and when there is the considerable disproportion between the compared objects or actions, assumptions gravitate to being any, and usually are far from reality" [10], in the technique of the assessment of efficiency of the SIIP at the choice of range of the scale for the assessment of indicators of social efficiency in the sphere of housing and communal services, education, health care, culture, physical culture and sports, transport the gradation of parameters in this directions at the level of "very weak, weak, equal, strong, very strong" which are well perceived and differentiated by the person is offered.

As the result of survey of 20 experts conducted within work in the areas for each of 6 directions the system from 10 indicators is received and the scale for their assessment is ranged. The system of indicators of the assessment of social efficiency from implementation of innovative-and-investment projects in cultures are provided in table 1. Change of indicators is estimated on the basis of percent of decrease or growth.

Table 1. System of indicators for the assessment of social efficiency from the implementation of the innovative-and-investment project in the sphere of culture.

\begin{tabular}{|c|l|c|c|}
\hline №№ & \multicolumn{1}{|c|}{ Dynamics of the indicator change } & $\begin{array}{c}\text { Value of the } \\
\text { indicator in } \\
\text { case of } \\
\text { change of } \\
\text { the } \\
\text { indicator to } \\
\text { the best }\end{array}$ & $\begin{array}{c}\text { Weight } \\
\text { coefficient } \\
\text { of the } \\
\text { indicator }\end{array}$ \\
\hline 1 & $\begin{array}{l}\text { Increase in the share of the museum items and archival } \\
\text { documents available to the viewer, including owing to the } \\
\text { use of innovative and the nanotechnologies protecting } \\
\text { materials and mechanisms from moisture }\end{array}$ & 1 & 0.8 \\
\hline 2 & $\begin{array}{l}\text { Increase in the share of 3-D museum pieces presented to } \\
\text { the viewer in the total quantities of museum pieces of fixed } \\
\text { assets }\end{array}$ & 1 & 0.6 \\
\hline 3 & $\begin{array}{l}\text { Increase in the share of online broadcasts of theatrical and } \\
\text { concert programmes }\end{array}$ & $\begin{array}{l}\text { Increase in the share of the restored unique and especially } \\
\text { important archival documents and exhibits in the total } \\
\text { quantity of the documents which are subject to restoration } \\
\text { and exhibits of this category, including due to new } \\
\text { technologies in restoration }\end{array}$ & 1 \\
\hline 5 & Increase in the share of new works of professional art in the & 1 & 0.4 \\
\hline
\end{tabular}




\begin{tabular}{|c|l|c|c|}
\hline & general repertoire of the organizations of performing arts & 1 & 0,6 \\
\hline 6 & $\begin{array}{l}\text { Increase in the availability of electronic services of libraries } \\
\text { to the population }\end{array}$ & 1 & 1 \\
\hline 7 & $\begin{array}{l}\text { Increase in the intellectual potential of the population and } \\
\text { formation of positive valuable orientations and standards of } \\
\text { behavior of inhabitants }\end{array}$ & 1 & 0.4 \\
\hline 8 & $\begin{array}{l}\text { Increase in the level of the use of lines of broadband access } \\
\text { per 100 people of the population due to all the technologies }\end{array}$ & $\begin{array}{l}\text { Increase in the share of the actions aimed on the } \\
\text { preservation and development of non-material cultural } \\
\text { heritage of the citizens of Russia in the total set of the } \\
\text { actions realized by cultural institutions of club formation }\end{array}$ & $\begin{array}{l}\text { Gronth of number of participants of club formations of } \\
\text { amateur folk art, participants of cultural and leisure actions, } \\
\text { including due to innovative transformations to the } \\
\text { organizations of cultural leisure }\end{array}$ \\
\hline
\end{tabular}

The indicator of social effect for each of the directions (health care, culture, education, transport, housing and communal services, physical culture and sports) is calculated according to the following formula:

$$
\text { Esoc }=\sum_{n}^{i=1} I s o c i \times K w i
$$

Where Esoc - social effect of the project implementation;

Isoci - the value of the indicator considering change of i-go of the indicator in the considered direction. In case of change of the indicator to the best - accepts value 1 , in the absence of the indicator growth or its change to the worse, the value 0 is appropriated to the indicator.

Kwi - weight coefficient of the social effect indicator.

The coefficient of the accounting of interests of future generations (Kbp) is estimated by summation of values of the indicators corresponding to change to the best of the indicators presented in a technique. In case of lack of influence of the indicator or his change for the worse, to the indicator the value equal 0 is appropriated.

Existence of change of indicators of social effect in the directions of the social sphere, and also indicators for calculation of coefficient of the accounting of interests of future generations, is estimated by each expert individually in forms of poll $[11,12]$. The konkordation coefficient calculated by results of answers of experts for decision-making on the project has to make more than 0.5 . Otherwise, discussion of dynamics of indicators is carried out to the commissions, the refill of forms by experts, and calculation of coefficient of coherence of opinions of experts. For more exact and objective assessment it is recommended to include the indicators offered in the technique in initial information on the project. The accounting of risk of realization of the SIIP is carried out by means of risk coefficient. The total rating assessment of the project is corrected taking into account probability of achievement by the project of the put results by multiplication of a rating assessment on the project on its value (1-coefficient risk level).

The coefficient of risk level is offered to be estimated on the basis of statistical data processing on similar in scope of application, technology, to novelty level to innovative and investment projects. 


\section{Discussion}

According to the developed technique, as well as on the basis of its approbation, it has been concluded that the social innovative-and-investment project is deemed accepted to realization at the achievement of the following indicators:

- the coefficient of significance value of the project makes up 0.25 and more;

- the coefficient of effectiveness of the project makes up 0.1 and more;

- the indicator of the social effect on the project makes up 0.2 and more;

- the coefficient of the accounting of interests of future generations is non-negative.

In case when at least one of the given indicators accepts value, which is below the established level, the social innovative-and-investment project is rejected as its realization does not bear any positive social consequences.

In case of the assessment of the efficiency of the social investment project as the special case of SIIP, calculation is perfromed according to 1 st algorithm, presented in the drawing provided that calculation of coefficient of significance value as it characterizes the level of novelty of innovations is excluded from an the assessment [13].

The social investment project is deemed accepted to realization upon the achievement of the following indicators:

- the coefficient of effectiveness of the project makes up 0.1 and more;

- the indicator of social effect on the project makes up 0.2 and more;

- coefficient of the accounting of interests of future generations is non-negative.

For the assessment of social efficiency of the commercial innovative-and-investment project in view of inexpediency the assessment of significance the value of the project, effectiveness of the project, and also the assessment of the budgetary efficiency of the project is excluded from calculation. As the result, the assessment of social efficiency of the commercial innovative-and-investment project is carried out on the basis of the following indicators: population which quality of life improves as the result of implementation of the project, creation of additional jobs during implementation of the project, social effect (in the directions of the social sphere) and coefficient of the accounting of interests of future generations [14].

The assessment of social efficiency of the commercial innovative-and-investment project is not defining at selection of the project to realization: within such assessment it is only possible to make the following conclusion - wheather the innovative-and-investment project includes any social effect or not. The commercial innovative-and-investment project is approved or rejected on the basis of the criteria of its economic efficiency $[15,16,17]$.

\section{Conclusion}

The presented approach to the assessment of efficiency is based that introduction of social innovative-and-investment projects leads to the improvement of quality of human life and comfort of conditions of accommodation, that is to growth of the final quality social indicators: to decrease in incidence and mortality, increase in birth rate and life expectancy, quality of education, culture and sports [18].

Within the calculation of the projects efficiency currently, quantitative characteristics are generally used. The official statistics also mainly based on some quantitative measuring instruments. Development of the social sphere is often connected with the creation of new municipal objects: schools, hospitals, higher education institutions, institutions of culture and sport, infrastructure component . The acceptance of the approach to the assessment of the results of innovative-and-investment design of the social sphere offered in work is connected with the solution of important methodical questions on formation of system of the indicators which are adequately reflecting improvement of functioning of objects of the social sphere, to compliance of these indicators to the international requirements, 
development of methods of collecting primary information and methods of an assessment of change of indicators.

\section{References}

1. E.V. Sibirskaya, O.A. Stroyeva, S.N. Martov, Innovations 5, 30-33 (2014)

2. N.D. Kondratiev, Big conjuncture cycles and the theory of anticipation (Economics, Moscow, 2002)

3. B. Santo, Innovation as the means of economic development (Progress, Moscow, 2008)

4. V.V. Glazkova, E.M. Marchenko, Methodical bases of an estimation of efficiency of the social innovative-investment project (Sobor-Media, Vladimir, 2015)

5. T. Saity, Decision making. Method of the hierarchies analysis (Radio and Communication, Moscow, 1993)

6. E.Yu. Chibisova, Assessment of financial efficiency of the investment project (Marketing, Moscow, 2004).

7. N.G. Verstina, N.N. Taskaeva, T.N. Kisel, E.M. Akimova, A.V. Fedosina, International Journal of Applied Engineering Research 10 (20), 41156 - 41163 (2015)

8. N.G. Verstina, T.N. Kisel, N.N. Taskaeva, E.Y. Chibisova, Life Science Journal 11(8), 326-330 (2014)

9. N.G. Verstina, N.N. Taskaeva, T.N. Kissel, E.M. Akimova, A.V. Fedosina, International Journal of Applied Engineering Research 10 (20), 41156 - 41163 (2015)

10. S. Morozov, N.N. Taskaeva, Man in India 7 (96), 2009-2023 (2016)

11. An.B. Mottaeva, As.B. Mottaeva, International Journal of Applied Engineering Research 11- 9, 6808-6816 (2016)

12. A. Gorshkov, V. Murgul, O. Oliynyk, MATEC, 53, 01045 (2016)

13. T. Miroshnikova, N. Taskaeva, MATEC 73, 07006 (2016)

14. I. Polyakova, E. Vasilyeva, Procedia Engineering 165, 1410-1416 (2016)

15. E.M. Akimova, E.M. Stein E.M., Y.S. Prokhorova, Journal of Advanced Research in Law and Economics 6(3), 472-487 (2015)

16. A. Pimenova, S. Kuzmina, N. Morozova, A. Mottaeva, MATEC Web of Conferences 73, 07018 (2016)

17. N.G. Verstina, E.M. Akimova, T.N. Kisel, E.Y. Chibisova, V.A. Lukinov, International Journal of Economics and Financial Issues 5 (3S), 217-223 (2015)

18. N.G. Verstina, T.S. Meshcheryakova, Biosciences Biotechnology Research Asia 12-2, 1411-1423 (2015) 